\title{
GUIDELINES FOR THE DESIGN OF (EDUCATIONAL) DIGITAL GAMES ON COMPLEX SOCIETAL ISSUES
}

\author{
Joelle-Denise Lux ${ }^{1}$, André Czauderna $^{2}$, Emmanuel Guardiola $^{2}$ \& Alexandra Budke $^{1}$ \\ ${ }^{1}$ University of Cologne, Institute for Geography Education \\ ${ }^{2}$ TH Köln, Cologne Game Lab \\ Correspondence: info@dispielgeo.de
}

\begin{abstract}
Designers of digital entertainment games and designers of games for education can learn from each other when it comes to gameplay mechanics, content and mediation techniques that enable a fun and at the same time educational experience for players. The following design guidelines bring together the perspectives of entertainment game industry and educators. Based on a range of studies, they present 11 recommendations to facilitate the design of games on complex social and socio-ecological issues such as climate change, migration, city development and resource conflicts - suitable for any designer who wants to provide an enriching game experience.
\end{abstract}

\section{INTRODUCTION}

Digital entertainment games are not merely a popular medium of adolescents to engage with in their free time (MPFS, 2018, 56), but they also oftentimes depict content relevant to learning - for example current societal challenges, such as climate change or sustainable city development, that are also part of geography education. For the educational sector, these games show potentials for learning motivation (e.g., Arnold, Söbke and Reichelt, 2019), explorative learning (e.g., Van Eck, 2006), or practicing problem-solving (e.g., Gaber, 2007), for instance. Games specifically designed for educational purposes may be better tailored to learning goals or curricular content, but are often criticized for offering a rather low degree of complexity and a limited amount of choices, inter alia, which results in reduced motivational potential compared to entertainment games (Sanford et al., 2015; Shen et al., 2009). From the perspective of learning theory, this is insofar problematic as successful processes of learning require the learners' motivation, self-efficacy, and a well-balanced level of complexity, which corresponds and adapts to learners' knowledge and skills (Gee, 2007). We therefore support the assumption that educational game designers can learn from the perspective of entertainment game 
designers, and vice versa. With this in mind, we - the team of DiSpielGeo, a joint project of the Institute for Geography Education of the University of Cologne and the Cologne Game Lab of the TH Köln, funded by the German Federal Ministry of Education and Research - conducted a series of studies (see our publications: Czauderna and Budke, 2020; Czauderna and Budke, 2021; Lux and Budke, 2020a; Lux and Budke, 2020b; Lux, Budke and Guardiola, in preparation). These studies focused on commercially successful and well-received games, mostly in the genre of simulation and strategy games, that include the geographical topics of climate change, urban development, migration, and/or resource use, such as Cities: Skylines, Civilization VI: Gathering Storm, or Tropico 6. Our research concerned aspects such as the games' system complexity, geographical content, facilitation of dynamic decision-making, realism, and principles of political education, utilizing 18 game analyses and 9 qualitative interviews with game designers. Based on the results of these studies, we derived recommendations for the design of games on complex societal challenges that can be used in geography education. The resulting guidelines are intended to provide guidance; of course, for certain learning objectives, deviations from the recommendations can be necessary. The guidelines have been tested and further improved in a workshop on game conceptualization with prospective game designers and geography teachers. Goal of these guidelines is to aid developers of games for learning, as well as of entertainment games that aim to give their players an enriching experience, in creating games that are both fun and educational.

\section{OVERVIEW OF OUR RECOMMENDATIONS}

1. Choose at least two current societal topics to incorporate in your game to show their interconnections!

2. Make your game as accessible as possible for students and teachers!

3. Research societal issues in academic and authentic sources and include scientists in your team - to facilitate depicting the real-life issues in their actual controversy and versatility!

4. Make simplifications based on comprehensibility and on considerations regarding cognitive overload, not player expectations!

5. Enable different paths to success and reflect controversial positions, to avoid influencing players ideologically!

6. Choose player roles that give the opportunity to make an impact on the represented societal topics! 
7. Design your game as a complex system to foster system thinking and (long-term) motivation!

8. Build your game around polytelic situations to facilitate challenging decisions and make realism interesting!

9. Moderate complex problems and polytelic situations via didactical features!

10. Give players the opportunity to interact with one another or with NPCs to negotiate proper solutions for geographical issues!

11. Represent the multi-perspectivity of the chosen societal topics and the versatility and complexity of their causes and effects!

\section{Choose at least two current societal topics to incorporate in your game to show their interconnections!}

Real societal topics, such as climate change or migration, do not only add educational, but also entertainment value to a game: They are popular among players and make for interesting, challenging, even emotional game contexts, as our interviewees reported. Most value is added when choosing at least two societal issues to depict, so you can show the interconnections between them. This can aid in preparing players for handling these challenges in real-life, in which decisions on one societal area, e.g. resource use, always exerts influences on others, e.g. climate change.

Current societal topics - such as city development, climate change, migration and sustainable resource use - are favored by game developers of many commercial strategy/simulation games such as Cities: Skylines, Civilization VI or ECO as themes for their games because they provide context and interesting conflicts, evoke emotions and are popular among players, amongst other aspects (Lux, Budke and Guardiola, in preparation). From the perspective of geography education this is a win-win: Major topics of geography education are incorporated into games because they are interesting, making it possible to use the games in educational contexts, and they are presented in an entertaining way, which may increase learners' interest in and engagement with the topics.

Our recommendation is to pick at least two of the topics and to link these within the game. Thereby, interconnections between the issues can be shown, such as that climate change 
accelerates through high demand in resources, that migration demands urban planning, or that city development needs to change with a changing climate (Lux \& Budke, 2020a, 33). Such interconnections also increase complexity, which makes the game more interesting for players and more suitable for acquiring a competence in dealing with complex systems (see also 7.). Not all chosen topics need to be in the center of attention and directly tied to the winning conditions, though. For example, in Fate of the World (FOTW), the main focus is on climate change, while resource use affects this topic via emissions from the consumption of energy resources. In Civilization VI: Gathering Storm and ECO, climate change and resource use are of equal importance. Other combinations that have proven successful and marketable are for example city development, migration and resource use, as in Tropico, or city development, climate change and resource use, as in Anno 2070.

\section{Make your game as accessible as possible for students and teachers!}

Think of students and teachers as a target group - which has special requirements for accessibility. To ensure that the game experience remains intact in classroom situations, try to design an easy (lateral) entry into the game, customization options and an early confrontation with the geographical topics.

Games can influence perceptions, concepts and attitudes of their players (e.g. Reyes and Adams 2010: 161; Schwartz, 2006: 316ff.). When designing a game around societal challenges, it becomes more than entertainment, it also plays a part in informing players about the represented topics, whether intentional or not. In many cases, as our interviews with game designers of popular strategy and simulation games disclosed, learning goals are in fact intentionally pursued in parallel to entertainment goals in commercial game design (Lux, Budke and Guardiola, in preparation). This makes students and teachers a potential target group not only of educational games, but also of entertainment games that involve real societal topics. The target group is essential to be kept in mind or even involved in the game design process (Lukosch et al., 2018), and this particular target group has special requirements regarding games. For one, time in class is limited - even when including time for homework. To enable a practical use in class, opportunities for entry at various points in the game are helpful, e.g., an option to start the game at advanced climate change or in an established city. Dividing the game into freely selectable missions can also be helpful in this context. Also, our analyses disclosed 
that at times it takes hours of gaming before being confronted with the included geographical challenges - as with the climate change in Civilization VI: Gathering Storm, which only occurs after passing several in-game eras. We recommend bringing in these topics as early as possible, and to intertwine them with the goals of the game - an example would be Fate of the World, which confronts players with climate change right from the beginning, as it is made the main topic of the game and the objective is to curb the global temperature rise. Additionally, it should be considered that the game is made accessible to teachers and learners who have little or no gaming experience to date. Therefore, the games should gradually increase in complexity and difficulty. In-game wikis, such as the one provided in Civilization, particularly on the represented geographical topics, can further aid in getting into the game and even serve as additional teaching tool. Overall, any additional material, such as Let's plays, accompanying texts or didactic commentary, as well as any customization settings, can help to make the game more accessible for teachers and pupils.

\section{Research societal issues in academic and authentic sources and include scientists in your team - to facilitate depicting the real-life issues in their actual controversy and versatility!}

As society becomes more and more complex and dynamic, so do their socio-ecological challenges. For being able to depict such topics in games in their multi-perspectivity, controversy, versatility and in their current state, information needs to be gathered in upto-date scientific and authentic sources or with the help of experts.

When depicting real societal topics in a game, a certain degree of external realism needs to be designed. External realism is about designing aspects of the game in a manner that resembles the real world, such as events that are plausible in real life (e.g. Busselle and Bilandzic, 2008; Ribbens, 2013; Lux, Budke and Guardiola, in preparation). It is self-evident that this type of realism needs to be based on informational research regarding the depicted topics. Additionally, such information gathering and the subsequent incorporation of external realism helps to create a logical, coherent game, here referred to as internal realism (Lux, Budke and Guardiola, in preparation). In our interview study with entertainment game designers who developed games with geographical relevance, all interviewees agreed on the importance of research (ibid.). However, oftentimes popular media like internet sources, novels, movies, or 
other games are favored over authentic or scientific sources (ibid). Designers additionally bring in their own beliefs, attitudes, and understandings (Czauderna and Budke, 2021; Lux, Budke and Guardiola, in preparation). In some cases, this leads to the societal topics being presented stereotypically, and to perpetuating common misunderstandings (ibid). Yet, designers should aim to represent the societal topics in their real-life controversy and versatility - for educational reasons, but also to add interest to the games. One way to achieve that is to consider scientific sources, such as papers or text book chapters, and/or authentic sources on the topics, such as well-researched newspaper articles or witness and expert reports. Attention should be paid to finding sources for different perspectives on the chosen societal topic, to facilitate the depiction of multi-perspectivity and controversy, as well as to the up-to-dateness of the sources, to make sure they represent the current state of knowledge. As such, we support the suggestion which Lukosch et al. (2018) made for games and simulations for research purposes, namely that designers should make use of "the latest scientific insights and knowledge from the application field for validation and verification" (ibid., 285). Apart from literature research, a way to facilitate this is to consult scientific experts on the presented topics. As game content is oftentimes kept secret until a certain point in development, we suggest including such experts directly in the development team, whenever possible (however, we acknowledge that particularly smaller development teams are not financially equipped for extending the team with experts and have other priorities). A model for such a team is the one of the collaborative environmental science game $E C O$, which consisted of both scholars and game developers.

\section{Make simplifications based on comprehensibility and on considerations regarding cognitive overload, not player expectations!}

Deviations from a realistic representation of the geographical topics are inevitable in game design. However, selective decisions or simplifications of content should be made in a conscious way, similar to didactical reduction, rather than based on player expectations. This approach can help in avoiding misrepresentations and perpetuations of stereotypes.

Though external realism is, to a certain degree, essential to depict real societal issues and phenomena, deviations from reality are inevitable in game design - for example, to ensure comprehensibility and better handling, to balance cognitive load or simply because reality is too complex to be simulated faithfully. Perfect adherence to the real world is not necessary for an educational game; in fact, no simulation can achieve that. Instead of attempting to achieve 
the impossible, a designer may approach the comparison of reality to imperfect games as didactic in its own right. However, according to our interviewees, oftentimes selective decisions are made based on player expectations and common beliefs regarding the represented topics rather than on thoughtful reductions of content (Lux, Budke and Guardiola, in preparation). This is because the players' expectations (perceived realism) are prioritized over learning goals, in order to not disillusion them (ibid.) - earnings before learnings, so to say. Such an approach may result in the perpetuation of stereotypes and misconceptions. We recommend designers of games that represent current societal topics such as climate change or migration to be more cautious when simplifying interrelations within these topics, and to base these simplifications on informed selective decisions. This process can be compared to so-called 'didactic reduction', in which the variety of the topic content is reduced based on the target group of learners, the focus is set on the core of the topic, and it is presented in a comprehensible way, without producing misconceptions (e.g., Lehner, 2020). Additionally, it would be valuable to be transparent about deviations from reality in the game, e.g. in an in-game wiki that explains where reality and game deviate, which could be used by teachers for a reflection in class, or by players in out-of-school contexts.

\section{Enable different paths to success and reflect controversial positions, to avoid influencing players ideologically!}

For the promotion of independent thinking and decision-making within societal topics, but also for making a game attractive for a broad target group, give players as much freedom of choice as possible. This concerns the diversity of actions to take, the inclusion of controversial positions on socio-ecological topics and the allowance for different ways to success.

In order to support the forming of political opinions and foster independent thinking/decision-making, the games' options for action should be diverse, allowing for as much freedom of choice as possible. The scope of possible decisions and actions should reflect controversial positions and not hide any legitimate positions (Czauderna and Budke, 2021, 97 101). The range of possible measures to act within the geographical topics should be broad, and include both preventative and curative options (Lux and Budke, 2020b, 13, 25-27). Taking climate change as an example, preventative would be renewable energy sources, alternative 
transportation, dietary changes, etc., and curative would be flood protection, irrigation measures, heat-resistant plants and the like. Additionally, game designers should make sure to reward different strategies for problem-solving equally - particularly concerning political decisions within the societal topics. Evaluation and feedback by the game should be as valueneutral as possible and imply that different paths can lead to success. The players should be enabled to realize their own ideas and to experiment with different, possibly controversial alternatives. Most importantly, players should not be manipulated in the direction of the developers' opinion. Overall, players should be motivated to think and decide independently according to their own developing moral and political standpoints (Czauderna and Budke, 2021, 97-101).

In our qualitative interviews, most entertainment game designers claim that they indeed try to influence players' decisions as little as possible ideologically. One way to enable different paths to success is offering different factions to play. An example are the factions in Anno 2070 that allow for two fundamentally different ways of dealing with climate change, as Volker Sassen, one of the game's designers, describes in an interview with us: “[...] one tries to stop climate change and live very environmentally conscious, namely the Ecos, and the Tycoons [...] who just continue to farm according to the current model and are highly productive and who do not pay further attention to the environment." Arguments for offering players a high degree of freedom are not only educational, but also concern the games' appeal for players. Andrea Fricke, a game designer on Anno 1800, argues that "the freedom of representing and expressing yourself is also a very important aspect to get players to motivate themselves internally." Moreover, many designers assume that their players do not want to be lectured. As Cliff Harris, the Democracy designer, states: “And I don't think players like playing a game where they've been told they're a bad person." Consequentially, players of his political simulation can be successful with both left-leaning and right-leaning politics. Such games address different types of players, with their respective interests and attitudes, and allow to experiment with approaches different from their own. In conclusion, games with a wide range of possible actions and a high degree of freedom in choices are suitable for promoting independent thinking/decision-making and marketable at the same time. 


\section{Choose player roles that give the opportunity to make an impact on the represented societal topics!}

For the facilitation of explorative learning, the roles given to players should enable them to make a significant impact on the represented societal topics. Rather than just being passively informed about the issues, powerful player roles enable learners to experiment within the geographical systems. Apart from that, such roles are attractive to players because they allow them to steer the game events in desired directions and outlive fantasies and creativity.

Simulation and strategy games, designed for entertainment, allow their players to take on powerful player roles, termed mayor, president, leader or similar, but rather resembling a god-like entity. These roles may be unrealistic, but have shown some major advantages. Firstly, taking over such roles is appealing to players, as they empower them to make an impact on the game world, let them live out curiosity and creativity, and match certain power fantasies (Lux, Budke and Guardiola, in preparation; Przybylski, Rigby and Ryan, 2010). Giving players a sense of self-efficacy and control contributes substantially to their motivation to deal with a game (Vorderer et al., 2004, 393-394). Secondly, they may also be beneficial for learning, as an "overpowered role" enables players to try out various measures, to influence several areas (of city development, politics, etc.) at the same time, to learn how their decisions affect the world, and to try different political approaches. They most importantly allow players to influence the game system, and with it the development of the societal issues, in a way that is usually beyond their reach, as individuals are in a much less powerful situation in real life. In doing so, they also require players to make important and difficult decisions that involve weighing and prioritizing, thus practicing decision-making in the light of conflicting interests (see also 8.). As Mark Terrano, a designer of Age of Empires II, puts it, players are given the opportunity to make "high-level decisions", which gives them "a sense of making [...] tradeoffs". Thus, we do recommend those powerful roles due to both entertainment purposes as well as their benefits for contextual, self-empowered, experimental learning. However, in classroom contexts, powerful player roles must be critically compared to roles of (political) actors in reality - if for example negotiation is missing in games, it should be addressed in class. In future games, the powerful player roles should be complemented by negotiation mechanics (see 10.). 


\section{Design your game as a complex system to foster system thinking and (long-term) motivation!}

Complexity makes a game more challenging and thereby appealing, but also adds educational value, as it can foster systemic thinking and system competence. Make use of the complex systems underlying societal topics to create games with a challenging, but not overwhelming complexity. Bring in various parameters, actors, scale levels and a high degree of cross-linking, in a comprehensible way.

The current socio-ecological challenges of society are highly complex. In order to teach about these topics and equip players to solve problems within them, the games must present the topics with a certain level of complexity. It can be assumed that games which design complex systems around the societal issues can promote systemic thinking and system competence needed to comprehend such issues (Lux and Budke, 2020b; Waddington and Fennewald, 2018). System competence is the ability to understand a complex issue as a system, to identify and comprehend its relevant elements, such as actors and factors, to model and predict its behavior, and to base actions taken on these insights (Frischknecht-Tobler, Kunz and Nagel 2008; Lux and Budke, 2020b; Mehren et al. 2018). Apart from the ability to foster such a competence, in simulation and strategy games complexity additionally enhances the appeal for players: Players of this genre seem to enjoy and even demand complexity, for instance, when they are required to deal with multiple depending parameters simultaneously, and it ensures their (long-term) motivation (Lux, Budke and Guardiola, in preparation).

According to results of our game analyses (Lux and Budke, 2020b, 6, 14-19, 28), increasing the number and diversity of parameters, particularly those connected to societal topics, such as "in-migration rate", "degree of soil sealing", etc., raises the level of complexity that players need to handle within the geographical issues. To ensure comprehensibility and traceability of actions' consequences, precise and measurable parameters are preferable to abstract ones - e.g., "CO2 emissions in ppb" and "global temperature change in ${ }^{\circ} \mathrm{C} / \mathrm{F} / \mathrm{K}$ " are preferable to "ecobalance" or "global warming rate" (as also recommended by Endl \& Preisinger, 2018). Unintentional follow-up effects of actions that resemble those in reality also contribute to making the game world a complex system that needs to be thought through by players. For example, e-mobility in Fate of the World increases energy demand, which, if 
players have not switched to climate friendly energy sources yet, accelerates climate change rather than slowing it down. As Waddington and Fennewald (2018) have tested with players of Fate of the World, thinking through such an interconnected system in games as well helps players to understand the complexity of the represented real-life cause and effect relationships. However, the effects should still be indirectly attributable to the cause, otherwise the player could not comprehend what led to the effect. In Democracy, such a traceability is achieved by the means of a graphical representation of parameter interconnections. Additionally, it also increases resemblance to complex systems in real life if different actors have an influence on the game system, such as the different nations in Civilization or the voter groups in Tropico and Democracy. Furthermore, acting on and affecting different scale levels (e.g., simulating environmental effects of resource use on the local, national, and global level) increases complexity and resemblance to the real world, and makes the games more relevant for the subject of Geography, as it is focused on spatial phenomena and dynamics (DGfG, 2020). While parameters are traditionally a feature of strategy and simulation games, the other design recommendations are easily transferrable to other genres: Unintended follow-up effects of actions, the perspectives of different actors, and action on various scale levels can also be included in more story-driven genres such as adventures.

Although complexity and the resulting challenge are reportedly motivational for many players and enable mastery moments that are highly satisfactory (Koster, 2013, 40), game designers must also be aware that complexity may be off-putting to some players. At the minimum it requires a certain degree of moderation (see 9.). Starting with a lower level of complexity and adding to it in the course of the game (e.g. a steady increase in the number of parameters or addition of scale levels) can also contribute to comprehensibility, better handling and, lastly, the learning effect. To make the game more accessible for teachers and students within the limited time in class, options such as scenarios for lateral entry into the game (e.g. choosing a certain state in a city's development or a degree of climate change), Wikis, customization options and other measures can be helpful (see 2.), and they do not stand in the way of designing a complex learning environment. 


\section{Build your game around polytelic situations to facilitate challenging decisions and make realism interesting!}

Within real societal issues, there are often conflicting goals, as they involve many areas and stakeholders and are regarded controversially. Make use of this fact to design decisionmaking situations with conflicting goals! Such situations further players' decision-making competence, and allow for the reportedly most interesting, impactful decisions.

The solution to complex societal problems requires the consideration of several, partly conflicting goals. Climate change is a prime example of such a problem as one has to reconcile the reduction of $\mathrm{CO}_{2}$ emissions on the one hand against people's desire to carry on with their $\mathrm{CO}_{2}$ intensive lifestyles (such as taking plane trips, owning a car or consuming meat and tropical fruits) on the other hand. Environmental measures may be in conflict with the capitalist economic model based on free trade, globalization, and aiming at continuous growth of gross domestic product. Ultimately, decision-making often includes multiple, conflicting perspectives. Solutions cannot solely be based on one measure, but require several complex measures, and great number of variables must be considered (see 7.). In the field of "judgement and decision-making", these kinds of problems are labelled "polytelic situations" (Funke, 2010, 134) - derived from the Greek term "politely", which means "many goals".

According to our game analyses, commercial simulation and strategy games confront their players with such conflicting goals and let them pursue a continuous series of interesting decisions (Czauderna and Budke, 2020, 8-10). In Fate of the World, for example, players must combat climate change and still deliver decent figures of human development index and gross domestic product. Typically for polytelic situations, the way of achieving a certain goal is not necessarily straightforward. Measures taken do not always (only) lead to the intended effects, and unintended side effects may appear, which is also the case in games when they simulate a complex system (see 7.) (Lux \& Budke, 2020b, 8-9, 27). For example, the construction of a factory in city builders such as Cities: Skylines or SimCity BuildIt might lead to jobs in the area, but also to pollution and unhappiness of direct neighbors. In the course of these games, players must "develop hypotheses about the inner structure of the system" (Dörner and Schaub, 1994, 2) to overcome its lack of transparency. Players must continuously choose the best possible next step as part of a wider series of actions, and adjust the overall strategy using the feedback of the game (Czauderna and Budke, 2020, 10). 
Evidence from player research suggests that for most players of simulation and strategy games, polytelic situations are a central reason for their motivation to play. They enjoy the challenge of balancing various conflicting goals, as well as the difficulty of complex decisionmaking. Players are also fond of thinking, planning, making long-term strategies, and considering consequences (Quantic Foundry, no date). In educational contexts, players' decision-making in these kinds of polytelic situations can be a starting point for in-depth classroom discussions about the solution of complex societal problems.

\section{Moderate complex problems and polytelic situations via didactical features!}

In order to make the complexity and polytely manageable for players, include a suitable amount of didactic mediation. Means of such mediation could for example be transparent feedback, well-presented options for action, virtual advisors or the option to accelerate, slow down or stop the in-game time.

In our game analyses, we found that certain structural features of simulation and strategy games mitigate the above-described challenges of complex problems and polytelic situations and thereby foster processes of learning (Czauderna and Budke, 2020). Overall, we discovered three techniques of didactic mediation that support players' practice of decision-making: (1) The arrangement of a manageable scope of possibilities - by limiting (to a certain degree), ordering, and presenting the decisions possible in the game; (2) the offering of lucid feedback to players' decisions (e.g., via visible reactions of the game system, in-game messages or virtual advisors); and (3) the modification of time (ibid, 11-20). The latter facilitates the practice and learning of dynamic decision-making in two ways: (a) The representation of a timespan that covers years to decades (event time) in much shorter play sessions (play time) - i.e., the acceleration of time and feedback - illustrates players the effects of decision-making that would otherwise take weeks, months, years, decades; and (b) the possibility to decide about the passage of time themselves (e.g., deciding about the end of turns, slowing down the game speed, pausing and replaying) allows players to think about and reflect their decisions and to repeat and experiment with them (ibid., 17-20). Furthermore, it may also be beneficial to provide assistance to players when needed, for example via virtual advisors, such as those in SimCity. Interactive maps, which use colored overlays to give an overview of the areas to be managed 
(similar to a geographical information system), are also helpful for players as orientation aid and basis for decision-making. Examples of this can be found in Tropico and ECO, where map layers for environmental pollution or infrastructure coverage are available. All those techniques of didactic mediation mitigate the complex problems and polytelic conflicts, i.e., make them comprehensible. Both complexity and mediation contribute to the enjoyment of playing a game and to the games' learning opportunities.

\section{Give players the opportunity to interact with one another or with NPCs to negotiate proper solutions for geographical issues!}

In reality, negotiation is key when trying to resolve problems arising in socio-ecological contexts. To make games more realistic, versatile and lastly educative, negotiation mechanics should be incorporated. These could involve other real players or non-player characters such as representatives of interest groups, parties and nations or individuals. Implementation options include chats, voting and other measures of direct democracy, and virtual congresses.

The current issues of society involve manifold stakeholders with differing interests, resulting in the polytelic decision-making situations described (Czauderna and Budke, 2020) (see 8.). In reality, solutions for problems within these issues need to take into account the differing perspectives and are best suitable when developed as a joint effort. In many games, particularly strategy and simulation games, players are given the power to decide everything on their own. This is problematic from our perspective, as comprehension of democratic negotiation processes, ability to take over multiple perspectives and practice of argumentation skills are key objectives in geography education (see e.g. Budke, 2012) and particularly relevant in solving societal problems. Also, opportunities for collaboration in games enhance social dynamics and make for a more fruitful learning experience, as has been tested with board games, for example (Peppler, Danish and Phelbs, 2013). As such, while we advertise for powerful player roles (see 6.), we recommend to curtail their almightiness for the sake of negotiation. The practice of decision-making should be simulated as a collaborative process among different actors representing a variety of perspectives - through the necessity to reach agreements with either non-player characters (NPCs) or other players (via multiplayer modes). In the games analyzed, we found some few examples that include such opportunities (Lux and 
Budke, 2020b, 21-22). The world congress with non-player characters in Civilization VI Gathering Storm allows for negotiation about measures regarding climate change, and the democratic system in the multiplayer open world ECO enables players to agree on laws (via voting), for example regarding environmental protection measures. In political simulations such as Tropico or Democracy, players at least indirectly need to consider the demands of different voter groups, which are communicated to the players. Other options could be interviewing NPCs, the inclusion of statements from real people or interest groups, a negotiation with real players via chat or with NPCs via fake chat. With measures like these, game designers may enhance the interaction within multiplayer titles, encourage cooperation, reduce the almightiness of player roles, and bring in surprising twists and turns to the course of the narrative. Most notably, it would increase the comparability to real life and encourage multiperspectival thinking.

\section{Represent the multi-perspectivity of the chosen societal topics and the versatility and complexity of their causes and effects!}

As mentioned earlier, current societal challenges are highly complex in their cause-effectrelationships, and are regarded controversially from a plethora of actors. When it comes to the content regarding these topics, try to reflect this multi-perspectivity, controversy, and the versatility of measures to take action as well as of causes and effects - this will not only be educational, but add to an interesting complexity. In the following, we will give some specific examples of geographical content that would be useful to include for enhancing games' educational potential. Not all of the aspects below are needed to create a game that is suitable for geography education; nonetheless, attention to the following aspects can reduce the perpetuation of stereotypes and common misunderstandings.

\section{Resource use and resource conflicts}

When choosing to include resource use, add the aspect of sustainability, which may include the finite nature of many natural resources such as coal and oil, the environmental and social effects of both the mining and the use of resources, and the re-thinking of the common game goal of economic growth. Additionally, resolutions to conflicts revolving around resources do not always have to be military! 
Resources play an important part in many strategy and simulation games - in fact, all of our analyzed games contain the topic of resource use to some degree (Lux \& Budke, 2020a, 30). The link between economics and resources becomes very clear in the games studied - for example, the importance of coal and oil for energy production (e.g. Frostpunk, Civilization), of fertile soil for agriculture (e.g. Tropico), of other natural resources such as water for supplying the population (e.g. Cities: Skylines, SimCity), or of raw materials for industry (e.g. Anno, Rise of Industry) (ibid.). Critical here is the goal of steady population and economic growth, which in many games is tied to winning conditions, as it propagates a steadily increasing, unsustainable exploitation of resources (ibid.). Other goals, such as targets for switching to renewable energy, building a circular economy, or targets for population satisfaction rather than growth, could already bring more sustainability into play. Sustainability is key for the topic of resource use when a game shall educate about it (see geography curricula, e.g., MSB, 2014, 24). What many games already do is to show the limits of resource extraction from individual deposits, and to incorporate the slow regeneration of renewable resources (such as of wood in $E C O)$. However, the general finiteness of resources such as coal, oil or sand, which is also a decisive factor when considering sustainable resource use, has so far rarely been addressed (one example is FOTW) (ibid.). Most of the analyzed games successfully incorporate environmental effects of the use of resources (air and soil pollution), few also include effects of resource mining (slags in ECO, emissions through resource mining in FOTW), and none show social problems of resource gathering, such as problems of relocations (ibid., 30-31). Future games can exhaust more possibilities in this context. Opportunities to illustrate the controversial nature of the issue also exist in relation to resource conflicts. In many games, resource shortages arise, some of which can be solved militarily (e.g. in Age of Empires), but also through trade (e.g. the trade systems in Banished and Anno). However, in reality resource conflicts are more diverse; problems of land grabbing, international and national inequalities in the distribution of resources and resulting socio-economic disparities are important issues within the topic (Lux and Budke, 2020a, 32) and involve diplomatic negotiation for problem-solving. These issues, paired with negotiation mechanics (see 10.), can make for more challenging and multiperspectival games. 


\section{Migration}

If you decide to incorporate migration into your games, disrupt the usual stereotypical representation: Simulate different types of migration, depict causes for migration movements, show not only negative effects on the economy, and give various options to act within this topic.

In our game analysis regarding the depiction of geographical topics, we found that migration positively contributes to the complexity of games, but we also worked out a range of deficits of the current depiction of the topics in a majority of the games analyzed (Lux \& Budke 2020a, 28ff.). Often the issue is presented in a very one-sided, stereotypical way, with only one form (either labor or refugee migration) and predominantly negative effects on the economy; concrete reasons for migration are mostly not given at all. Yet the topic itself is very complex in reality and could be presented more profitably for both learning and game challenge. For one, motifs for migration are diverse (see Budke \& Kuckuck, 2018, 11ff.); motifs such as family and cultural causes, wars and persecution, or better educational opportunities are underrepresented in strategy and simulation games so far (Lux \& Budke 2020a, 28). Also, types such as irregular migration, internal migration (e.g. rural-urban migration), return migration and seasonal work are not addressed in the games analyzed, but are important to the topic as well (ibid.). Climate migration, as represented in Fate of the World, is currently highly debated and can make for interesting games, too. Furthermore, we advertise for a stronger orientation towards real effects of different types of migration on the game world - while at present the depiction of negative effects on the economy predominates in many games, there are also many positive effects to consider that could make a game less stereotypical. A rare example from existing games is Tropico 6, in which skilled migrants can be recruited to give the economy a push. But not only economic effects are important, there are also effects on society to consider, and the sub-topic of integration can be interesting for games as well. Also, we recommend the simulation of both immigration and emigration, with measures to handle both (e.g. emigration policies) - this enhances the challenge and is more externally realistic. Overall, a more multifaceted depiction of the topic in games may help to disrupt stereotypes when it comes to the topic of migration. 


\section{Climate change}

In case climate change is among the topics you want to present, show more versatility and complexity of causes and effects than many other games around this issue. Simulate both direct effects of the global temperature rise, such as melting of glaciers and sea level rise, as well as indirect effects, such as the occurrence of diseases or increased food prices. Climate change triggers can also be direct or indirect, and there are tipping points that can suddenly accelerate development - a welcome challenge for any game on climate change.

Climate change is one of the most pressing issues of today, making the topic interesting for any game designer that wants to depict the most popular and recent societal challenges - as have stated, for example, the creators of Anno 2070 and Democracy $3 \& 4$ (Lux, Budke and Guardiola, in preparation). Our game analysis has shown that current strategy and simulation games which model influences on and of Earth's climate do include many of the most relevant direct causes and effects of climate change (Lux \& Budke 2020a, 26ff.). All games make a connection to the use of fossil fuels, be it in energy generation or in transport, and most games also make a connection to forest loss as an indirect trigger for climate change. Missing in the majority of games is the role of agriculture as one of the major drivers (ibid., 26), both directly through $\mathrm{CO}_{2}$ emissions, for example from livestock, and indirectly through deforestation (for an overview of effects of agriculture on the climate see Schlatzer, 2011). Also, tipping points of our current climate, which can accelerate development abruptly, such as the melting of Earth's permafrost soils and the disintegration of the Greenland ice shield, only played a role in FOTW in our game selection (Lux \& Budke 2020a, 26). This is where game designers could improve future games, as these are the relationships that make the climate system so complex and are not already common knowledge. The same applies to effects of climate change. In addition to direct, known effects such as glacier melting, sea ice shrinkage and sea level rise, indirect effects such as an increase in food prices due to more cost-intensive agriculture (as made in Democracy 3), or effects on ecosystems (as in ECO), or the spread of diseases due to habitat shifts of their vectors, etc., should also be simulated. Because climate change is a problem of global proportions and has such diverse causes and involves a plethora of conflicting goals, it can only be contained through the joint efforts of numerous actors. This is why the negotiation mechanisms described in section 10 are particularly important in this field. Overall, the topic of climate change can be used to increase the complexity of a game significantly, and it is currently one of the most popular, highly debated topics that can be included into games. 


\section{City development}

The topic of urban development thrives from the involvement of different actors. Hence, try not to focus only on logistics and the logical design of cities (which is important as well), but also include the needs and perspectives of various groups of inhabitants, and the connection between the city and its surrounding. Also, think modern when making city development the challenge of your game: Sustainable development of cities is a pressing issue of today's society, so include options to create green cities that are prepared for the climate and the demands of tomorrow.

City development is a popular topic of strategy and simulation games, with the subgenre of city builders making it their central theme (such as Cities: Skylines, SimCity or Cities in Motion). One of the most educationally beneficial features of the majority of such games is that players can explore the connection between different concepts relevant in cities, such as transport, industry, green space planning, education infrastructure, energy and water infrastructure, and similar. The topic of sustainable urban development is also recently making its way into the gaming landscape - for example, the possibilities for greening facades and for private solar panels in Cities: Skyline's add-on Green Cities. There are many more opportunities in this area, such as a greater focus on public transportation, building circular economies, creating bike lanes, and the like. One aspect that could be improved in future games is the representation of the inhabitants. They are often portrayed as a mass that can hardly be differentiated or not at all (Gaber, 2007, 116; Lux \& Budke, 2020b, 20), but in reality they have very diverse requirements for urban development. A good option for ameliorating is the inclusion of different interest groups and negotiation mechanics, as described under 10. Another aspect that could be improved to enhance educational value is strengthening the connection between the virtual city and its surrounding. Commuter effects, in- and out-migration and polluting effects of industrial zones that extent beyond the city's border are just some of the examples that play a role in real-life cities. Overall, the thematic complex of urban development offers many creative opportunities for game developers to design an interesting, complex and at the same time educational game.

\section{FUNDING}

This research was funded by the German Federal Ministry of Education and Research (BMBF), grant numbers 01JD1810A and 01JD1810B. 


\section{REFERENCES}

Arnold, U., H. Söbke and Reichelt, M. (2019) 'SimCity in Infrastructure Management Education'. Education Sciences 2019(9), 209:1-209:16.

Budke, A. (2012) "„Ich argumentiere, also verstehe ich.“ Über die Bedeutung von Kommunikation und Argumentation im Geographieunterricht'. In Budke, A. (Ed.) Kommunikation und Argumentation. Braunschweig: Diercke, pp. 5-18.

Budke, A. and Kuckuck, M. (2018) Migration und Geographische Bildung. Stuttgart: Steiner.

Busselle, R. and Bilandzic, H. (2008) 'Fictionality and perceived realism in experiencing stories: A model of narrative comprehension and engagement', Communication Theory, 18(2), pp. 255-280.

Czauderna, A. and Budke, A. (2020) 'How Digital Strategy and Management Games Can Facilitate the Practice of Dynamic Decision-Making', Education Sciences, 10(4), p. 99. doi: 10.3390/educsci10040099.

Czauderna, A. and Budke, A. (2021) 'Game Designer als Akteure der politischen Bildung', MedienPädagogik: Zeitschrift für Theorie und Praxis der Medienbildung, 38, pp. 94-116. doi: 10.21240/mpaed/38/2021.01.25.X.

DGfG - Deutsche Gesellschaft für Geographie (ed.) (2020) Bildungsstandards im Fach Geographie für den Mittleren Schulabschluss mit Aufgabenbeispielen. 10th edn. Bonn, Germany: Selbstverlag der DGfG.

Dörner, D. and Schaub, H. (1994) 'Errors in Planning and Decision-making and the Nature of Human Information Processing', Applied Psychology, 43(4), pp. 433-453. doi: 10.1111/j.14640597.1994.tb00839.x.

Endl, A. and Preisinger, A. (2018) 'Den Klimawandel spielbar machen - Diskursive Strategien der Darstellung von Umweltproblemen in Strategiespielen', Paidia. Zeitschrift für Computerspielforschung. Available at: http://www.paidia.de/?page_id=11592.

Frischknecht-Tobler, U.; Kunz, P.; Nagel, U. (2018) 'Systemdenken-Begriffe, Konzepte und Definitionen.' In Frischknecht-Tobler, U., Nagel, U., Seybold, H. (Eds.) Systemdenken. Wie Kinder und Jugendliche Komplexe Systeme Verstehen Lernen. Pestalozzianum: Zürich, Switzerland, pp. 11-32. 
Funke, J. (2010) 'Complex problem solving: a case for complex cognition?', Cognitive Processing, 11(2), pp. 133-142. doi: 10.1007/s10339-009-0345-0

Gaber, J. (2007) 'Simulating Planning: SimCity as a Pedagogical Tool'. Journal of Planning Education and Research 27, 113-121. DOI: 10.1177/0739456X07305791

Gee, J. P. (2007) What video games have to teach us about learning and literacy. Rev. and updated ed. New York: Palgrave Macmillan.

Koster, R. (2013) Theory of fun for game design. 2nd Edition. Sebastopol, CA, USA: O'Reilly Media.

Lehner, M. (2020) Didaktische Reduktion. Bern: Haupt.

Lukosch, H. K. et al. (2018) 'A Scientific Foundation of Simulation Games for the Analysis and Design of Complex Systems', Simulation \& Gaming, 49(3), pp. 279-314. doi: $10.1177 / 1046878118768858$.

Lux, J.-D. and Budke, A. (2020a) ‘Alles nur ein Spiel? Geographisches Fachwissen zu aktuellen gesellschaftlichen Herausforderungen in digitalen Spielen', GW Unterricht, 160(4), pp. 22-36. https://doi.org/10.1553/gw-unterricht160s22

Lux, J.-D. and Budke, A. (2020b) 'Playing with Complex Systems? The Potential to Gain Geographical System Competence through Digital Gaming', Education Sciences, 10(5), p. 130. doi: 10.3390/educsci10050130.

Lux, J.-D., Budke, A. and Guardiola, E. (in preparation) 'Games versus reality? How game designers deal with current topics of geography education'.

Mehren, R., Rempfler, A., Buchholz, J., Hartig, J. and Ulrich-Riedhammer, E. M. (2018) 'System Competence Modeling: Theoretical Foundation and Empirical Validation of a Model Involving Natural, Social, and Human-Environment Systems.' J. Res. Sci. Teach. 2018, 55, pp. 685-711.

MPFS (Medienpädagogischer Forschungsverbund Südwest) (2018) JIM-Studie 2018 - Jugend, Information, Medien: Basisuntersuchung zum Medienumgang 12- bis 19-Jähriger. https://www.mpfs.de/fileadmin/files/Studien/JIM/2018/Studie/JIM_2018_Gesamt.pdf

MSB (Ministerium für Schule und Weiterbildung NRW) (2014) Kernlehrplan für die Sekundarstufe II Gymnasium/Gesamtschule in Nordrhein-Westfalen: Geographie. Düsseldorf: MSB. Available at: 
https://www.schulentwicklung.nrw.de/lehrplaene/upload/klp_SII/ek/KLP_GOSt_Geographie. pdf

Peppler, K., Danish, J. A., \& Phelps, D. (2013) 'Collaborative Gaming: Teaching Children About Complex Systems and Collective Behavior'. Simulation \& Gaming, 44(5), 683-705. https://doi.org/10.1177/1046878113501462

Przybylski, A. K., Rigby, C. S. and Ryan, R. M. (2010) 'A motivational model of video game engagement', Review of general psychology, 14(2), pp. 154-166.

Quantic Foundry (no date) Gamer Motivation Model. Reference Sheets \& Details (V2). Available at: https://quanticfoundry.com/wp-content/uploads/2019/04/Gamer-MotivationModel-Reference.pdf.

Reyes, I. and Adams, S. (2010) 'Screening Play: Rules, Wares, and Representations in “Realistic” Video Games'. Journal for Computer Game Culture, 4(2), 149-166.

Ribbens, W. (2013) 'Perceived game realism: a test of three alternative models', Cyberpsychology, Behavior, and Social Networking, 16(1), pp. 31-36.

Sanford, K. et al. (2015) 'Serious games: video games for good?', E-Learning and Digital Media, 12(1), pp. 90-106.

Schlatzer, M. (2011) Tierproduktion und Klimawandel. Ein wissenschaftlicher Diskurs zum Einfluss der Ernährung auf Umwelt und Klima. Wien: Lit.

Shen, C., H. Wang and Ritterfeld, U. (2009) 'Serious Games and Seriously Fun Games'. In Ritterfeld, U., M. Cody P. Vorderer, P. (Eds.) Serious games: Mechanisms and Effects. Routledge, New York, 48-61.

Schwartz, L. (2006) 'Fantasy, Realism, and the Other in Recent Video Games'. Space and Culture 9, 313-325. DOI: 10.1177/1206331206289019

Van Eck, R. (2006) 'Digital game-based learning. It's not just the digital natives who are restless'. EDUCAUSE Review 41(2), 55-63.

Waddington, D. I. and Fennewald, T. (2018) 'Grim FATE: Learning About Systems Thinking in an In-Depth Climate Change Simulation', Simulation \& Gaming, 49(2), pp. 168-194. doi: $10.1177 / 1046878117753498$. 